\title{
Germanium Doping to Improve Carrier Mobility in CdO Films
}

\author{
A. A. Dakhel \\ Department of Physics, College of Science, University of Bahrain, P.O. Box 32038, Sakhir, Bahrain
}

Correspondence should be addressed to A. A. Dakhel; adakhil@sci.uob.bh

Received 16 January 2013; Accepted 12 March 2013

Academic Editor: Jianguo Lu

Copyright (C) 2013 A. A. Dakhel. This is an open access article distributed under the Creative Commons Attribution License, which permits unrestricted use, distribution, and reproduction in any medium, provided the original work is properly cited.

\begin{abstract}
This investigation addresses the structural, optical, and electrical properties of germanium incorporated cadmium oxide (CdO : Ge) thin films. The focus was on the improvement in carrier mobility $\mu$ to achieve high transparency for near-infrared light and low resistivity at the same time. The properties were studied using X-ray diffraction, SEM, spectral photometry, and Hall measurements. All CdO : Ge films were polycrystalline with high texture orientation along [111] direction. It was observed that it is possible to control the carrier concentration $\left(N_{\mathrm{el}}\right)$ and mobility $(\mu)$ with Ge-incorporation level. The mobility could be improved to a highest value of $\sim 91 \mathrm{~cm}^{2} / \mathrm{V}$.s with Ge doping of $0.25 \mathrm{wt} \%$ while maintaining the electrical resistivity $\rho$ as low as $2.76 \times 10^{-4} \Omega \cdot \mathrm{cm}$ and good transparency $\sim 80 \%$ in the NIR spectral region. The results of the present work proved to select Ge as dopant to achieve high carrier mobility with low resistivity for application in transparent conducting oxide (TCO) field. Generally, the properties found make $\mathrm{CdO}$ : Ge films particularly interesting for the application in optoelectronic devices like thin-film solar cells.
\end{abstract}

\section{Introduction}

Transparent conduction oxides (TCOs) like $\mathrm{ZnO}$, CdO, $\mathrm{SnO}_{2}, \mathrm{In}_{2} \mathrm{O}_{3}$, and $\mathrm{NiO}$ are degenerate semiconducting group. They exhibit typical n-type conduction, which is caused by a deviation from stoichiometry due to the low formation energies for intrinsic donor defects, such as natural structural metal interstitials $\left(\mathrm{M}_{\mathrm{i}}\right)$ and oxygen vacancies $\left(\mathrm{V}_{\mathrm{O}}\right)$. It was found that it is possible to control TCO optoelectronic properties by managing and controlling their structural defects. Therefore, the TCOs have widespread use in many advanced technologies, like flat panel displays and solar energy systems [1]. Therefore, it is necessary to examine ways for improving their optoelectronic functions. These enhancements could be realized by a suitable doping, which increases the carrier mobility $\left(\mu_{\mathrm{el}}\right)$ and consequently the conductivity but without reduction in the transparency.

The present work deals with CdO. It is one of TCOs with an n-type electrical resistivity of $10^{-2}-10^{-4} \Omega \cdot \mathrm{cm}$ and good transparency in the visible and NIR spectral regions with a direct bandgap of 2.2-2.7 eV [2-4]. The carrier mobility in $\mathrm{CdO}$ films is considerably dependent on growth method and conditions, like the type of the substrate and its temperature. For example, the room-temperature carrier mobility in $\mathrm{CdO}$ film grown by MOCVD method on glass substrate at $412^{\circ} \mathrm{C}$ was $105 \mathrm{~cm}^{2} / \mathrm{V} \cdot \mathrm{s}$ [5]. This high mobility was attributed to a reduction in neutral impurity scattering (NIS) due to improved grown film crystallinity rather than ionized impurity or grain boundaries (GBs) [5].

The carrier mobility in CdO films could be improved by doping with different metallic ions. It was established experimentally that doping of host $\mathrm{CdO}$ by ions of radius slightly smaller than that of $\mathrm{Cd}^{2+}$, like $\mathrm{Tl}[6], \mathrm{Y}[7]$, In $[8,9]$, and Sm [10], could improve the electronic mobility and conductivity of carriers. However, doping of host $\mathrm{CdO}$ with dopant ions of "much" smaller size like Cr, W, and B could more effectively improve the carrier mobility [11-13].

The present investigation concerns germanium $\mathrm{Ge}^{4+}$ as dopant of 6-coordination-number $(\mathrm{CN})$ radius $5.3 \times 10^{-2} \mathrm{~nm}$, which is "much" smaller than that of $\mathrm{Cd}^{2+}\left(9.5 \times 10^{-2} \mathrm{~nm}\right)$ [14]. However, doping of host $\mathrm{CdO}$ with Ge ions has not yet been investigated, although such doping was conducted for other TCOs like $\mathrm{ZnO}[15,16]$. The present fundamental work reports the effect of germanium doping on the structural, electrical, optical, and optoelectronic properties of host CdO. It will be seen that $\mathrm{Ge}$ doping of $\mathrm{CdO}$ is efficient in the construction of electronic transport ways for improving the carrier mobility in comparison with other dopants and could 
be successfully used for technical applications based on its IRTCO characteristics.

\section{Experimental Procedure}

Ge-doped CdO thin films were deposited in a vacuum chamber of residual oxygen atmosphere of about $1.3 \times 10^{-3} \mathrm{~Pa}$. The substrates were ultrasonically cleaned glass slides. The starting materials, pure Ge and CdO (Fluka A. G./Germany), were evaporated alternatively (layer by layer) in a vacuum chamber by alumina baskets (Midwest Tungsten Service, USA). The as-grown films were totally oxidised and stabilised with flash annealing in air at $400^{\circ} \mathrm{C}$ for $1 \mathrm{~h}$ keeping samples inside the closed furnace for slow natural cooling to room temperature. All samples were prepared in almost the same conditions including the reference pure $\mathrm{CdO}$ film. The evaporated masses were controlled with a piezoelectric microbalance crystal sensor (Philips FTM5). The thicknesses were measured after annealing using an MP100-M spectrometer (Mission Peak Optics Inc., USA) to be $0.10-0.22 \mu \mathrm{m}$. Films were deposited in different sets to study the effect of doping level. The wt $\%$ of dopant Ge ions to $\mathrm{Cd}$ ions in $\mathrm{CdO}$ films was determined during the morphological study by a scanning electron microscope SEM (SEM/EDX microscope Zeiss EVO) to be $0.10 \%, 0.19 \%, 0.25 \%, 0.27 \%$, and $0.31 \%$, and accordingly the samples were named, like $0.25 \%$ Ge sample. The structural properties of the prepared films were studied using X-ray diffraction (Philips PW 1710) with $\theta-2 \theta$ curves in the range $20-75^{\circ}$ and a $\mathrm{Cu} \mathrm{K}_{\alpha}$ radiation $(0.15406 \mathrm{~nm})$. Normal incidence transmission $T(\lambda)$ and reflection $R(\lambda)$ measurements were done in UV-VIS-NIR spectral region $(300-3000 \mathrm{~nm})$ on a Shimadzu UV-3600 double beam spectrophotometer. The electrical measurements were performed with a standard Van der Pauw method with aluminium dot contacts in a magnetic field of about one Tesla and using a Keithley 195A digital multimeter and a Keithley 225 current source.

\section{Results and Discussion}

3.1. Structural Characterisation. Figure 1 shows the $\mathrm{X}$-ray diffraction (XRD) patterns of the prepared pure and Gedoped $\mathrm{CdO}$ films on glass substrates. These patterns reveal that all the investigated films are cubic Fm $3 \mathrm{~m}$ CdO structure. The undoped CdO film was polycrystalline with energetically preferred [111] orientation of lattice constant $0.4695 \mathrm{~nm}$, as given in [17]. Due to Ge doping, the host CdO films grown on glass substrate became more [111] oriented. As a measure of relative preferred orientation (RPO), we consider the intensity ratio $\left(I_{(111)} / I_{(200)}\right)$ in pure and Ge-doped CdO. As shown in Figure 2, the RPO increased strongly getting a maximum for $0.25 \%$ Ge sample, which becomes almost a [111] singly oriented crystal. As another consequence of Ge doping, the lattice parameter (calculated by least squares method) decreased with increasing of Ge content, as shown in Figures 1 and 2. This can be explained, in general, by smaller ionic size of dopant $\mathrm{Ge}^{4+}$ ions and the nature of mechanism of $\mathrm{G}^{2+}$ ions incorporation in host $\mathrm{CdO}$ crystalline structure (that will be discussed later).

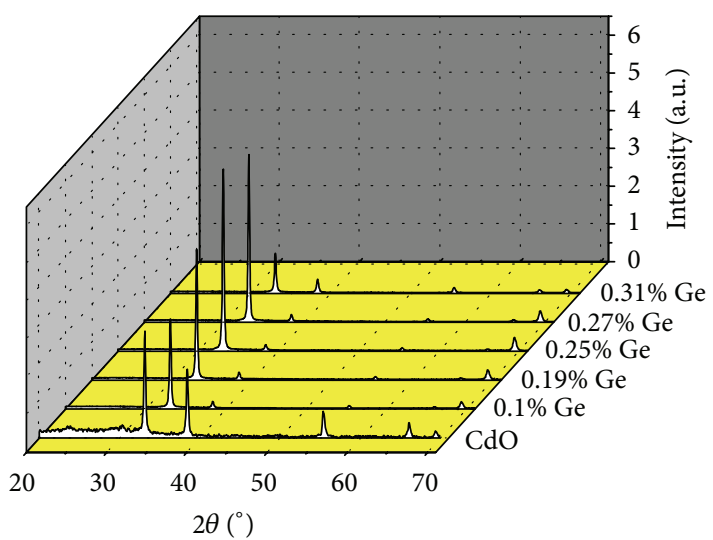

Figure 1: X-ray diffraction patterns for pure and Ge-doped CdO films deposited on glass substrates. The radiation used was $\mathrm{Cu} \mathrm{K}_{\alpha}{ }^{-}$ line.

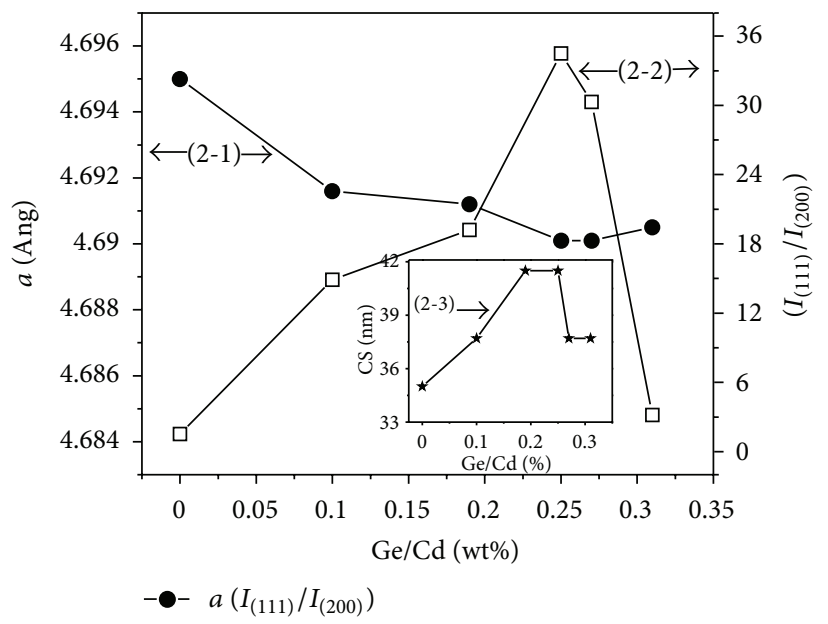

FIgURE 2: The variation of host $\mathrm{CdO}$ crystalline lattice parameter (2-1), [111] preferred orientation (2-2), and crystallite size (2-3) with Ge-incorporation level.

There is not any peak found corresponding to Ge or its oxide phase in the XRD patterns of Ge-doped CdO. This implies that $\mathrm{Ge}$ ions were dissolved in the lattice of $\mathrm{CdO}$. There are several possibilities for $\mathrm{Ge}$ ions to be incorporated in the host $\mathrm{CdO}$ crystalline lattice structure; they could occupy structural interstitial positions, occupy empty locations of $\mathrm{Cd}$ ions, or replace $\mathrm{Cd}$ ions. The real doping by replacement of $\mathrm{Cd}^{2+}$ ions with $\mathrm{Ge}^{4+}$ ions forming substitutional solid solution (SSS) needs several conditions to be fulfilled. The Shannon ionic radius difference of $\mathrm{Cd}^{2+}$ and $\mathrm{Ge}^{4+}$ is $44 \%$ [14], which is much larger than $15 \%$ necessary for the formation of SSS, according to the well-known HumeRothery rules. Furthermore, Ge-oxide crystalline structure (hexagonal) is different from that of $\mathrm{CdO}$ (cubic), which supports the un-favourability of Ge oxide to form an SSS with CdO. However, the close electronegativities (1.7 and 1.8 Pau for $\mathrm{Cd}$ and $\mathrm{Ge}$, resp.) support the favourability of forming SSS. Thus, the occupation of locations in the structural interstitial positions of $\mathrm{CdO}$ lattice with $\mathrm{Ge}^{4+}\left(\mathrm{Ge}_{\mathrm{i}}\right)$ ions is most likely 


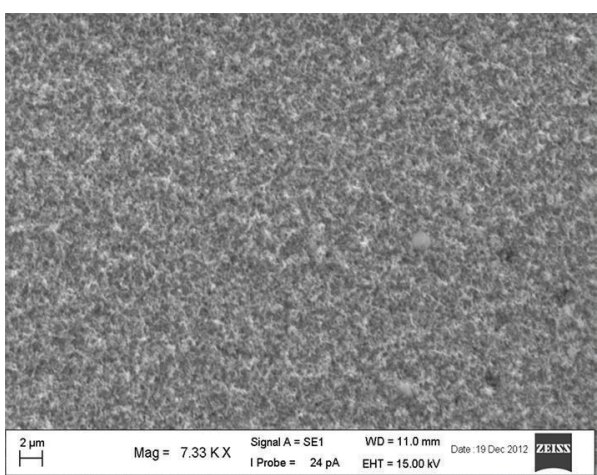

(a)

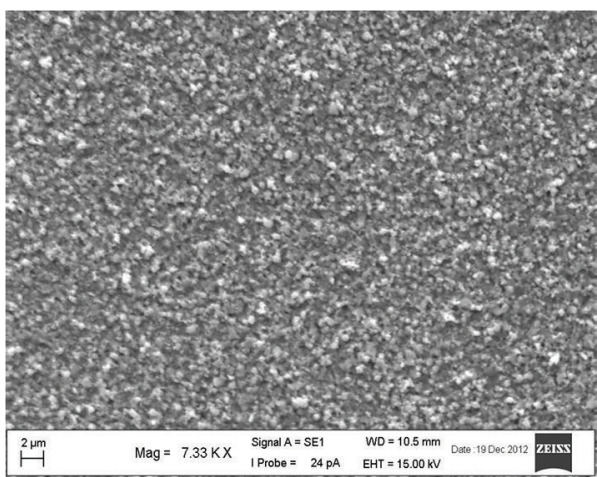

(c)

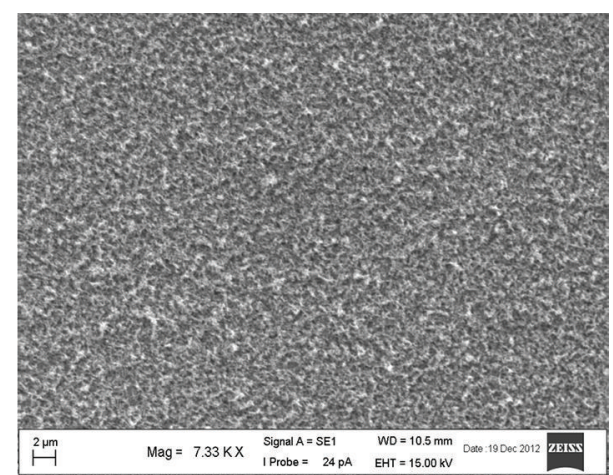

(b)

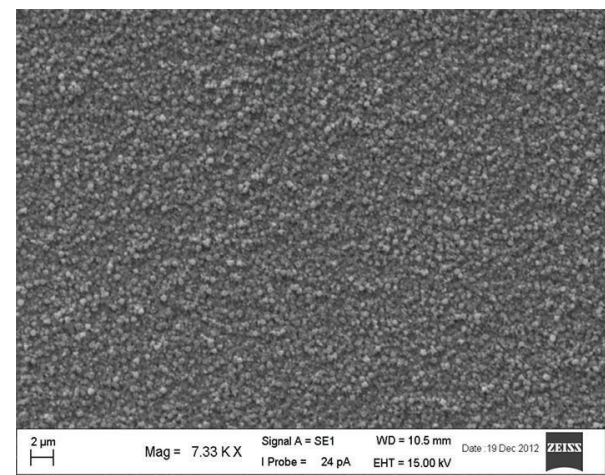

(d)

FIGURE 3: SEM micrographs of (a) undoped CdO, (b) 0.1\% Ge-doped CdO, (c) 0.19\% Ge-doped CdO, and (d) 0.25\% Ge-doped CdO films.

to happen at incorporation. Such incorporation disturbs the charge balance of the unit cell that can be settled by creation of $\mathrm{Cd}^{2+}$ ion vacancies $\left(V_{c d}\right)$ and/or formation of interstitial oxygen $\left(\mathrm{O}_{\mathrm{i}}\right)$. These variations cause decrease in lattice parameter since $\mathrm{Ge}^{4+}$ ion is smaller than $\mathrm{Cd}^{2+}$ ion. Furthermore, some of the $\mathrm{Ge}^{4+}$ ions that occupy interstitial positions might move by the thermal motion, small size, and high diffusivity and occupy $\mathrm{Cd}^{2+}$-ion vacancies $\left(V_{\mathrm{cd}}\right)$ making real (or SSS-type) doping.

The mean X-ray crystallite size (CS) was estimated from the intensive (111) reflection by using Scherrer equation [18]: CS $=0.9 \lambda / \beta \cos \theta$, where $\lambda$ is the $\mathrm{X}$-ray wavelength $(0.1540 \mathrm{~nm}), \beta$ is the full-width at half maximum (FWHM) of the diffraction peak (in radian), and $\theta$ corresponds to the peak position. The CS was $35 \mathrm{~nm}$ for undoped CdO film that slightly increases with Ge incorporation to $38-42 \mathrm{~nm}$, as shown in Figures 2 and 3. In general, this implies that the present samples are nanocrystallites. Furthermore, as the CS is considered as a good tool to estimate the crystallinity of the film, then the film crystallinity improves as $\mathrm{Ge} \%$ content increases up to $0.19 \% \mathrm{Ge}$. Then, for incorporation level of more than $0.25 \%$, the film gradually deteriorated.

The SEM study shows the morphological variations in the $\mathrm{CdO}$ films because of $\mathrm{Ge}$ doping. Figure 3 shows the SEM micrographs of undoped CdO (Figure 3(a)), $0.1 \%$ Gedoped (Figure 3(b)), 0.19 Ge-doped (Figure 3(c)), and 0.25\% Ge-doped (Figure 3(d)) CdO samples. It can be seen that pure $\mathrm{CdO}$ and $0.1 \% \mathrm{Ge}$-doped $\mathrm{CdO}$ films have woolly shape
TABLE 1: The measured electrical parameters (resistivity $(\rho)$, mobility $\left(\mu_{\mathrm{el}}\right)$, and carrier concentration $\left.\left(N_{\mathrm{el}}\right)\right)$ and bandgap $\left(E_{g}\right)$ for pure and Ge-incorporated $\mathrm{CdO}$ films grown on glass substrate.

\begin{tabular}{lcccc}
\hline Sample & $\begin{array}{c}\rho \\
\left(\times 10^{-4} \Omega \cdot \mathrm{cm}\right)\end{array}$ & $\begin{array}{c}\mu_{\mathrm{el}} \\
\left(\mathrm{cm}^{2} / \mathrm{V} \cdot \mathrm{s}\right)\end{array}$ & $\begin{array}{c}N_{\mathrm{el}} \\
\left(\times 10^{20} \mathrm{~cm}^{-3}\right)\end{array}$ & $\begin{array}{c}E_{g} \\
(\mathrm{eV})\end{array}$ \\
\hline $\mathrm{CdO}$ & 201 & 7.03 & 0.44 & 2.3 \\
$0.10 \% \mathrm{Ge}$ & 20.7 & 18.97 & 1.58 & 2.38 \\
$0.19 \% \mathrm{Ge}$ & 4.53 & 37.37 & 3.68 & 2.33 \\
$0.25 \% \mathrm{Ge}$ & 2.76 & 90.70 & 2.49 & 2.32 \\
$0.27 \% \mathrm{Ge}$ & 6.06 & 91.5 & 1.13 & 2.34 \\
$0.31 \% \mathrm{Ge}$ & 33.9 & 26.4 & 0.69 & 2.44 \\
\hline
\end{tabular}

microtopography. For more Ge content, this morphological structure gradually converted to a granular in $0.19 \%, 0.25 \%$, and $0.31 \%$ Ge-doped films with almost round grains of size (GS) $100-140 \mathrm{~nm}$. Furthermore, the SEM study proved uniform distribution of $\mathrm{Ge}$ ions in the films.

3.2. DC Electrical Properties. The electrical properties (conductivity $(\sigma)$, mobility $\left(\mu_{\mathrm{el}}\right)$, and carrier concentration $\left.\left(N_{\mathrm{el}}\right)\right)$ were measured for pure and Ge-incorporated $\mathrm{CdO}$ films grown on glass substrates by a standard Van der Pauw method, and the average results are presented in Table 1 and Figure 4. The experimental error due to the Al-contact spot size was estimated to be about $5 \%$. The measurements 


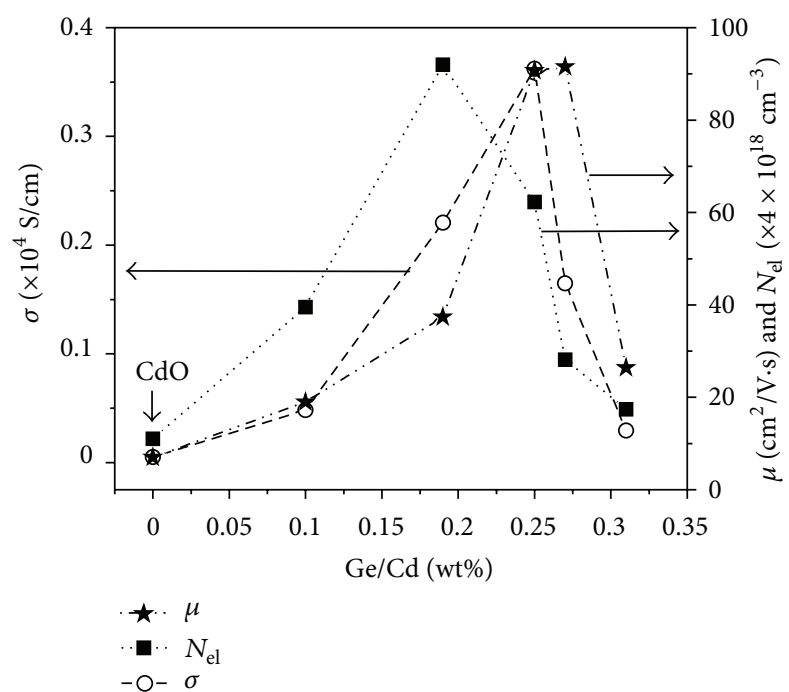

FIGURE 4: Variation of resistivity $(\rho)$, carrier concentration $\left(N_{\mathrm{el}}\right)$, and mobility $(\mu)$ with Ge-incorporation level of host CdO film grown on glass substrates.

show that the pure and all Ge-incorporated CdO films are n-type degenerate semiconductors. This means that $\mathrm{Ge}$ doping to host $\mathrm{CdO}$ leads to that Fermi level lies in the conduction band and doped $\mathrm{CdO}$ exhibits n-type character. The conductivity of pure host CdO thin film $(39.75 \mathrm{~S} / \mathrm{cm})$ was initially found to increase rapidly to $783.1 \mathrm{~S} / \mathrm{cm}$ with small amount of $0.1 \%$ Ge incorporation and then getting the utmost value $\left(3.663 \times 10^{3} \mathrm{~S} / \mathrm{cm}\right)$ for $0.25 \%$ Ge film, after which it decreased with the increasing of the Ge content. Similarly, the carrier concentration of host $\mathrm{CdO}\left(4.4 \times 10^{19} \mathrm{~cm}^{-3}\right)$ was also found to increase up to the utmost value $\left(3.68 \times 10^{20} \mathrm{~cm}^{-3}\right)$ for $0.19 \%$ Ge sample and then decrease with increasing Gd incorporation. The mobility attained the utmost value of about $91 \mathrm{~cm}^{2} / \mathrm{Vs}$ at $0.25-0.27 \% \mathrm{Ge}$ concentration. The increase in carrier concentration of host CdO film with addition of small amount of $\mathrm{Ge}^{4+}$ ions indicates, in general, that most of the incorporated $\mathrm{Ge}^{4+}$ ions act as donors. However, higher $\mathrm{Ge}$ incorporation in $\mathrm{CdO}$ lattice results in a gradual enhancement of certain carrier compensators like defects. This results in a reduction of measured free carrier concentration. Similar explanation was also adopted and examined by X-ray photoelectron spectroscopy with Cr-doped $\mathrm{ZnO}$ [19]. It is interesting to mention that the obtained dependences shown in Figure 4 are similar in forms to those obtained in [20] for doping of $\mathrm{CdO}$ with $\mathrm{Al}$, of 6-CN ionic radius $2.32 \times 10^{-2} \mathrm{~nm}$, which may support the vision given in the introduction. The enhancement followed by reduction of conductivity and mobility of carriers in $\mathrm{CdO}$ : Ge (Figure 4) could be explained in conjunction with the structural variations due to Ge incorporation by the following model. With $\mathrm{Ge}^{4+}$ doping, two oppositely competitive effects emerged, by which the conduction-parameters variation with Ge doping could be explained. Doping with small concentration of $\mathrm{Ge}^{4+}$-donors improves all the conduction parameters especially the mobility by improving the conduction provision of free carriers. For higher Ge-doping

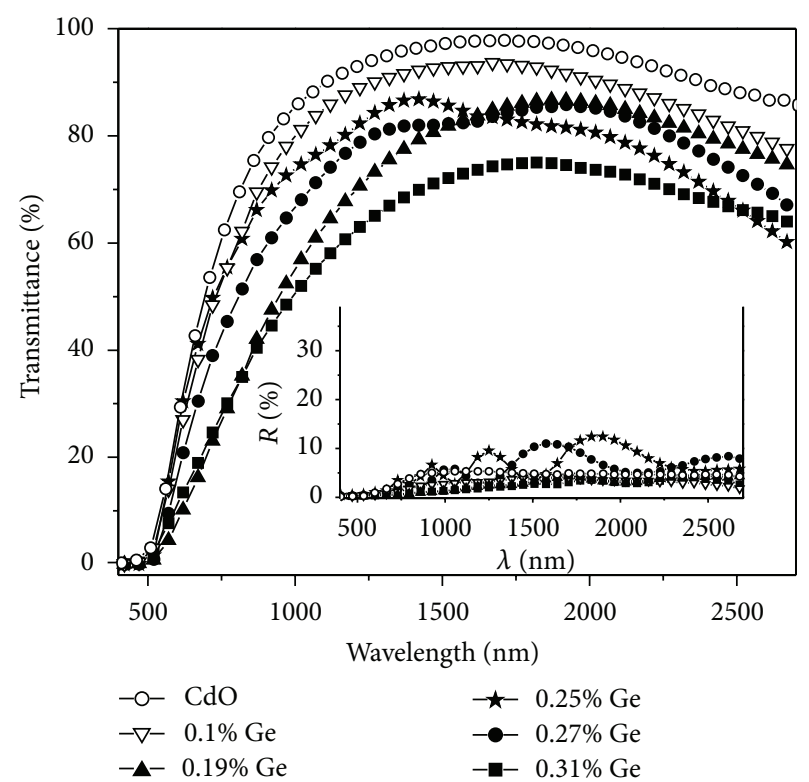

FIGURE 5: Spectral normal transmittance and reflectance of the pure and Ge-incorporated CdO films deposited on glass substrates.

level, the created $\mathrm{Cd}$ vacancies $\left(V_{\mathrm{Cd}}\right)$ and oxygen interstitials $\left(\mathrm{O}_{\mathrm{i}}\right)$ increased. These p-type defects can gradually compensate and consequently reduce conduction electron density in addition to inhibiting them, which reduces their mobility. In the result, all electrical properties reduced, as observed for Ge-doping level of larger than $0.25-0.27 \%$. This means that there is a critical concentration, at which the doped $\mathrm{CdO}$ reaches the greatest conductivity and mobility. In comparison with CdO doped with ions of "much" smaller size than that of $\mathrm{Cd}^{2+}$, the mobility attained $85.2 \mathrm{~cm}^{2} / \mathrm{V} \cdot \mathrm{s}$ for $1.3 \% \mathrm{Cr}-$ doped CdO, $39.0 \mathrm{~cm}^{2} / \mathrm{V}$.s for $0.1 \% \mathrm{~W}$-doped $\mathrm{CdO}$, and $45-$ $47 \mathrm{~cm}^{2} / \mathrm{V}$-s for 6-8\% B-doped CdO [11-13], which means that doping with $0.25-0.27 \%$ Ge ions leads to a better value of mobility, from TCO point of view.

The carrier mean free path ( $\mathrm{mfp})$ is defined as [21, 22] $\operatorname{mfp}=(h / 2 e)\left(3 N_{\mathrm{el}} / \pi\right)^{1 / 3} \mu$, where $h$ is the Planck constant and $e$ is the electronic charge. The highest value of mfp among the studied samples was $11.6 \mathrm{~nm}$ for $0.25 \% \mathrm{Ge}$. This value is much smaller than CS and GS. Thus, the carrier scattering by phonons, Ge impurities, and lattice defects has the major contribution compared to scattering by crystallite and grain boundaries. This conclusion is supported by the theoretical work of Zhang and Ma [22], in which they have concluded that for the degenerate polycrystalline TCO films with relatively large crystallite sizes and high carrier concentrations (higher than $5 \times 10^{18} \mathrm{~cm}^{-3}$ ), the grain boundary scattering on electrical carriers makes a small contribution to limit the mobility of the films, and the main scattering mechanisms are ionized impurity scattering and lattice phonons.

3.3. Optoelectronic Properties. The spectral normal transmittance $T(\lambda)$ and reflectance $R(\lambda)$ of the prepared Geincorporated $\mathrm{CdO}$ films grown on corning glass substrate in the UV-VIS-NIR region $(300-3000 \mathrm{~nm})$ are depicted in Figure 5. The maxima $\left(\lambda_{m}\right)$ of the transmittance $T(\lambda)$ spectra 


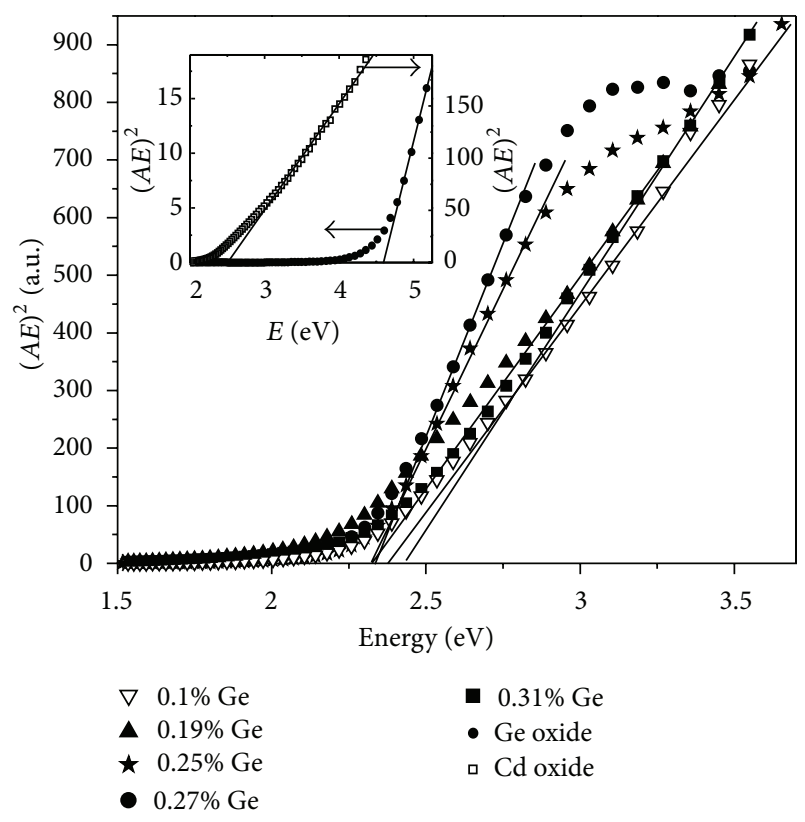

Figure 6: Tauc plot for Ge-doped CdO films. The inset shows Tauc plot for undoped $\mathrm{CdO}$ and Ge-oxide films.

are in the NIR region; that is, the better spectral transparent region $(T>70 \%)$ of the films is the NIR region of $\lambda>$ $750 \mathrm{~nm}$. In addition, the high-wavelength side of the transmittance curves $T(\lambda)$ of the doped $\mathrm{CdO}$ samples shows a clear damping due to the high density of free electrons. The absorbance $A(\lambda)$ that can be calculated by $A(\lambda)=\ln [(1-$ $R) / T$ ] [23] is used to evaluate the direct optical bandgap $E_{g}$ by Tauc method [24]:

$$
A E=B_{\mathrm{op}}\left(E-E_{g}\right)^{0.5}
$$

where $B_{\text {op }}$ is the film's constant. The extrapolation of the $(A E)^{2}$ versus $E$ plot for any film, as shown in Figure 6, gives the direct bandgap value (Table 1). The inset of Figure 6 shows the Tauc plot for pure $\mathrm{Ge}$-oxide $\left(\mathrm{GeO}_{x}\right)$ film prepared by thermal oxidation $\left(400^{\circ} \mathrm{C} / 1 \mathrm{~h}\right)$ in air of evaporated Ge film; the bandgap was $4.6 \mathrm{eV}$, which is close to $4.3 \mathrm{eV}$ found in [25]. For undoped $\mathrm{CdO}$ film, the bandgap obtained is in the range $(2.2 \mathrm{eV}-2.6 \mathrm{eV})$, which is known for $\mathrm{CdO}$ films prepared by different techniques [2]. The bandgap varies with Ge incorporation as shown in Figure 7; it shrinks by $\sim 6 \%$ with light $(0.1 \%)$ doping and reaches a minimum value of $2.32 \mathrm{eV}$ with $0.25 \% \mathrm{Ge}$-doping level. Thus, bandgap can be engineered with $\mathrm{Ge} \%$ doping.

The variation of bandgap with Ge incorporation has two components: the bandgap widening (BGW) [26] and bandgap narrowing (BGN) [27]. Thus, phenomenologically it is possible to correlate the bandgap variations with the carrier concentration by considering both BGW and BGN. The $\mathrm{BGW}$ is given by $\mathrm{BGW}=S_{\mathrm{BGW}} N_{\mathrm{el}}^{2 / 3}$, where $S_{\mathrm{BGW}}^{\text {th }}=1.348 \times$ $10^{-18} \mathrm{eV} \cdot \mathrm{m}^{2}$ [26]. The BGN is given by BGN $=\left(S_{\mathrm{BGN}}^{(1)} N_{\mathrm{el}}^{2 / 3}+\right.$ $S_{\mathrm{BGN}}^{(2)} N_{\mathrm{BGN}}^{1 / 3}$ ), where $S_{\mathrm{BGN}}^{(1)}=S_{\mathrm{BGW}}^{\text {th }} / 3$ and $S_{\mathrm{BGN}}^{(2)}=2.836 \times 10^{-9} /$ $\varepsilon_{r}$ [28]. The effective dielectric constant $\varepsilon_{r}$ is considered as

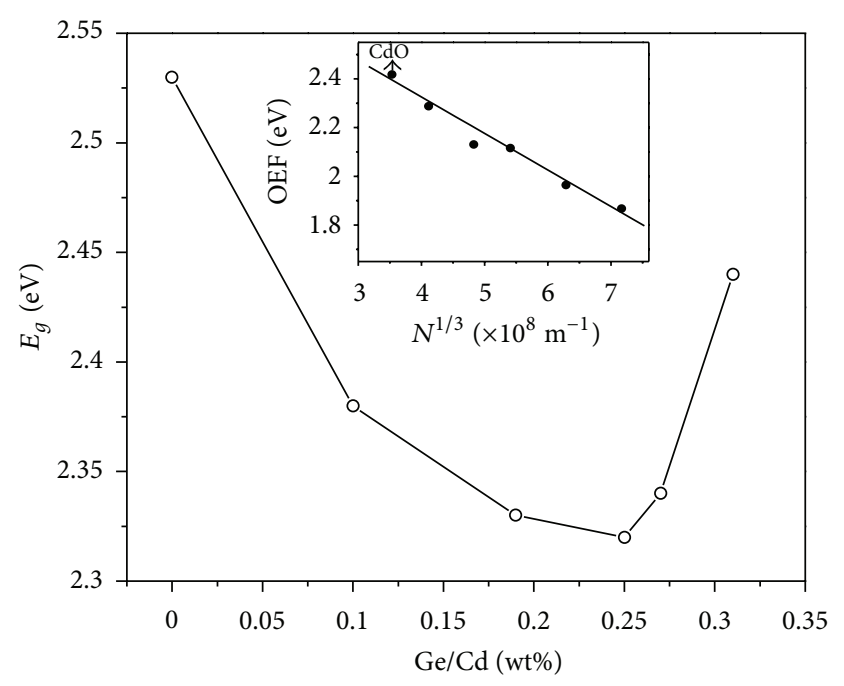

Figure 7: Variation of bandgap $\left(E_{g}\right)$ of host CdO films with Geincorporation level. The inset shows the $N_{\mathrm{el}}^{1 / 3}$-dependence of the $\mathrm{OEF}=\left(E_{g}-S_{\mathrm{BGW}, \mathrm{BGN}} N_{\mathrm{el}}^{1 / 3}\right)$. The straight line shows the best fit with equation (2).

long-wavelength dielectric constant $\left(\varepsilon_{\infty}\right)$, which is equal to about $\varepsilon_{\infty}=n^{2}=1.6^{2}$ for pure CdO. Thus,

$$
\begin{aligned}
\Delta E_{g} & =E_{g}-E_{g 0}=\mathrm{BGW}-\mathrm{BGN} \\
& =S_{\mathrm{BGW}, \mathrm{BGN}} N_{\mathrm{el}}^{2 / 3}-S_{\mathrm{BGN}}^{(2)} N_{\mathrm{el}}^{1 / 3}+C_{f},
\end{aligned}
$$

where $C_{f}$ is a fitting parameter and $S_{\mathrm{BGW}, \mathrm{BGN}}=S_{\mathrm{BGW}}-$ $S_{\mathrm{BGN}}^{(1)}=8.98 \times 10^{-19} \mathrm{eV} \cdot \mathrm{m}^{2}$. Straight line was obtained by plotting optoelectronic function $(\mathrm{OEF})$ : $\mathrm{OEF}=\left(E_{g}-\right.$ $S_{\mathrm{BGW}, \mathrm{BGN}} N_{\mathrm{el}}^{1 / 3}$ ) versus $N_{\mathrm{el}}^{1 / 3}$, as shown in the inset of Figure 7, which gives $S_{\mathrm{BGN}}^{(2)}=1.4 \times 10^{-9} \mathrm{eV} \cdot \mathrm{m}$ that is very close to the theoretical values $1.10 \times 10^{-9} \mathrm{eV} \cdot \mathrm{m}$.

\section{Conclusions}

The structural study shows that the included $\mathrm{Ge}^{4+}$ ions were dissolved in the crystalline lattice of $\mathrm{CdO}$. The incorporated $\mathrm{Ge}^{4+}$ ions disturb the charge balance of the unit cell that can be settled by creation of $\mathrm{Cd}^{2+}$ ion vacancies $\left(V_{\mathrm{Cd}}\right)$ and/or insertion of interstitial oxygen $\left(\mathrm{O}_{\mathrm{i}}\right)$. The incorporated dopant $\mathrm{Ge}^{4+}$ ions behave as donors while the $\left(V_{\mathrm{Cd}}\right.$ and $\mathrm{O}_{\mathrm{i}}$ ) species behave like p-type defects. The competition of these two opposite influence doers controls the conduction parameters of Ge-content CdO films. The carrier mobility varies with Ge-incorporation level attaining utmost value of about $91 \mathrm{~cm}^{2} / \mathrm{V}$.s with $0.25-0.27 \%$ Ge concentration while maintaining the electrical resistivity at $2.73 \times 10^{-4} \Omega \cdot \mathrm{cm}$. This value is higher than that found with $\mathrm{Cr}_{-}, \mathrm{W}-$, and B-incorporated CdO films prepared by the same method and conditions and thus considered as one of the highest values found for doped $\mathrm{CdO}$ grown on glass substrate. The improvement of the mobility was observed, accompanied 
with improving of crystallinity and crystalline [111] orientation. From infrared-transparent-conducting oxide (IR-TCO) point of view, germanium is sufficiently effective for $\mathrm{CdO}$ light doping. The doping creates structural and electronic energy spectrum variations that consequently shrink the bandgap. The variation of the bandgap with doping level was calculated in the framework of the available models.

\section{References}

[1] S. Calnan and A. N. Tiwari, "High mobility transparent conducting oxides for thin film solar cells," Thin Solid Films, vol. 518, no. 7, pp. 1839-1849, 2010.

[2] Z. Zhao, D. L. Morel, and C. S. Ferekides, "Electrical and optical properties of tin-doped CdO films deposited by atmospheric metalorganic chemical vapor deposition," Thin Solid Films, vol. 413, no. 1-2, pp. 203-211, 2002.

[3] D. M. Carballeda-Galicia, R. Castanedo-Pérez, O. JiménezSandoval, S. Jiménez-Sandoval, G. Torres-Delgado, and C. I. Zúñiga-Romero, "High transmittance CdO thin films obtained by the sol-gel method," Thin Solid Films, vol. 371, no. 1, pp. 105$108,2000$.

[4] M. Burbano, D. O. Scanlon, and G. W. Watson, "Sources of conductivity and doping limits in $\mathrm{CdO}$ from hybrid density functional theory," Journal of the American Chemical Society, vol. 133, no. 38, pp. 15065-15072, 2011.

[5] A. W. Metz, J. R. Ireland, J. G. Zheng et al., "Transparent conducting oxides: texture and microstructure effects on charge carrier mobility in MOCVD-derived CdO thin films grown with a thermally stable, low-melting precursor," Journal of the American Chemical Society, vol. 126, no. 27, pp. 8477-8492, 2004.

[6] A. A. Dakhel, "Effect of thallium doping on the electrical and optical properties of CdO thin films," Physica Status Solidi (A), vol. 205, no. 11, pp. 2704-2710, 2008.

[7] Y. Dou, R. G. Egdell, T. Walker, D. S. L. Law, and G. Beamson, "N-type doping in CdO ceramics: a study by EELS and photoemission spectroscopy," Surface Science, vol. 398, no. 1-2, pp. 241-258, 1998.

[8] A. Wang, J. R. Babcock, N. L. Edleman et al., "Indium-cadmium-oxide films having exceptional electrical conductivity and optical transparency: clues for optimizing transparent conductors," Proceedings of the National Academy of Sciences of the United States of America, vol. 98, no. 13, pp. 7113-7116, 2001.

[9] R. Asahi, A. Wang, J. R. Babcock et al., "First-principles calculations for understanding high conductivity and optical transparency in $\operatorname{In}_{x} \mathrm{Cd}_{1-x} \mathrm{O}$ films," Thin Solid Films, vol. 411, no. 1, pp. 101-105, 2002.

[10] A. A. Dakhel, "Transparent conducting properties of samarium-doped CdO," Journal of Alloys and Compounds, vol. 475, no. 1-2, pp. 51-54, 2009.

[11] A. A. Dakhel, "Investigation on high carrier mobility in chromium incorporated CdO thin films on glass," International Journal of Thin Films Science and Technology, vol. 1, pp. 25-33, 2012.

[12] A. A. Dakhel, "Electrical and optical investigations on Tungsten-incorporated CdO thin films," Journal of Electronic Materials, vol. 41, no. 9, pp. 2405-2410, 2012.

[13] A. A. Dakhel, "Structural, optical and electrical measurements on boron-doped CdO thin films," Journal of Materials Science, vol. 46, no. 21, pp. 6925-6931, 2011.
[14] R. D. Shannon, "Revised effective ionic radii and systematic studies of interatomic distances in halides and chalcogenides," Acta Crystallographica A, vol. 32, part 5, pp. 751-767, 1976.

[15] M. Jiang, Z. Wang, and Z. Ning, "Study of structural and optical properties of Ge doped ZnO films," Thin Solid Films, vol. 517, no. 24, pp. 6717-6720, 2009.

[16] Y. B. Lv, Y. Dai, K. Yang et al., "Density functional investigation of structural, electronic and optical properties of Ge-doped ZnO," Physica B, vol. 406, no. 20, pp. 3926-3930, 2011.

[17] Powder Diffraction File, Joint Committee for Powder Diffraction Studies (JCPDS) file No. 05-0640.

[18] E. F. Kaelble, Ed., Handbook of X-Rays for Diffraction, Emission, Absorption, and Microscopy, McGraw-Hill, New York, NY, USA, 1967.

[19] R. S. Ajimsha, A. K. Das, B. N. Singh, P. Misra, and L. M. Kukreja, "Correlation between electrical and optical properties of Cr: $\mathrm{ZnO}$ thin films grown by pulsed laser deposition," Physica $B$, vol. 406, no. 24, pp. 4578-4583, 2011.

[20] N. Wongcharoen, T. Gaewdang, and T. Wongcharoen, "Electrical properties of Al-doped CdO thin films prepared by thermal evaporation in vacuum," Energy Procedia, vol. 15, pp. 361-370, 2012.

[21] M. Chen, Z. L. Pei, X. Wang et al., "Intrinsic limit of electrical properties of transparent conductive oxide films," Journal of Physics D, vol. 33, no. 20, article 2538, 2000.

[22] D. H. Zhang and H. L. Ma, "Scattering mechanisms of charge carriers in transparent conducting oxide films," Applied Physics A, vol. 62, no. 5, pp. 487-492, 1996.

[23] W. Q. Hong, "Extraction of extinction coefficient of weak absorbing thin films from special absorption," Journal of Physics $D$, vol. 22, no. 9, article 1384, 1989.

[24] J. Tauc and F. Abelesn, Eds., Optical Properties of Solids, North Holland, Amsterdam, The Netherlands, 1969.

[25] V. V. Afanasev, A. Stesmans, A. Delabie, F. Bellenger, M. Housse, and M. Meuris, "Electronic structure of $\mathrm{GeO}_{2}$-passivated interfaces of (100) Ge with $\mathrm{Al}_{2} \mathrm{O}_{3}$ and $\mathrm{HfO}_{2}$," Applied Physics Letters, vol. 92, no. 2, Article ID 022109, 3 pages, 2008.

[26] J. I. Pankove, Optical Processes in Semiconductors, Dover, New York, NY, USA, 1975.

[27] Y. Z. Zhang, J. G. Lu, Z. Z. Ye et al., "Effects of growth temperature on Li-N dual-doped p-type $\mathrm{ZnO}$ thin films prepared by pulsed laser deposition," Applied Surface Science, vol. 254, no. 7, pp. 1993-1996, 2008.

[28] A. A. Dakhel, "Optoelectronic properties of Eu- and H-codoped CdO films," Current Applied Physics, vol. 11, no. 1, pp. 11-15, 2011. 

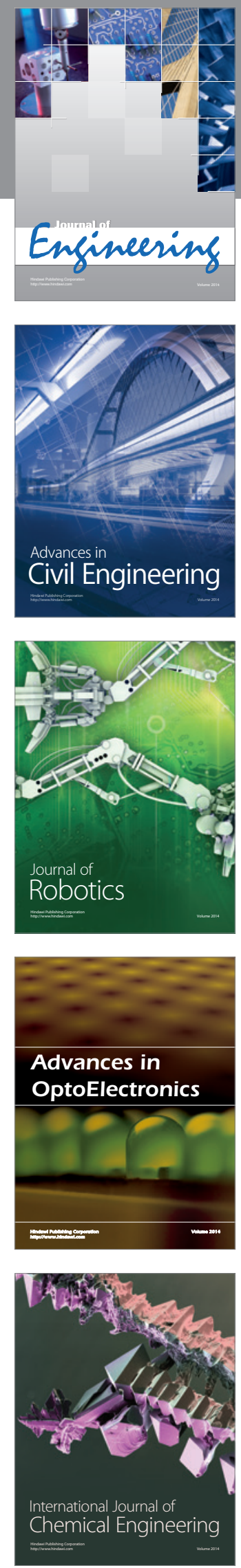

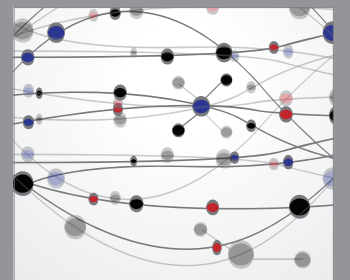

The Scientific World Journal
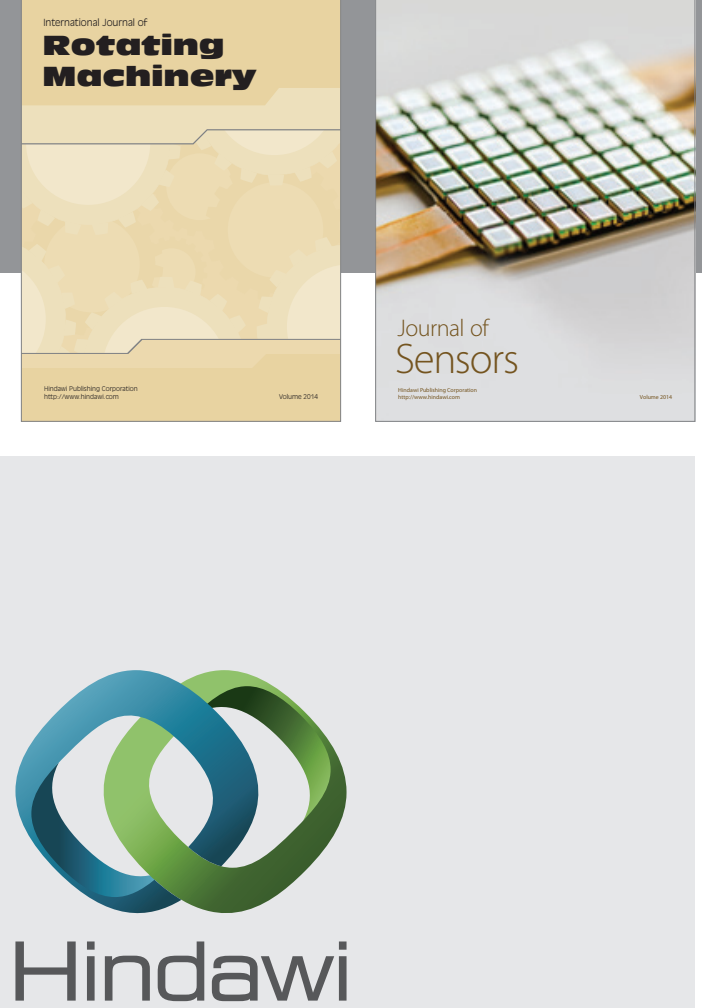

Submit your manuscripts at http://www.hindawi.com
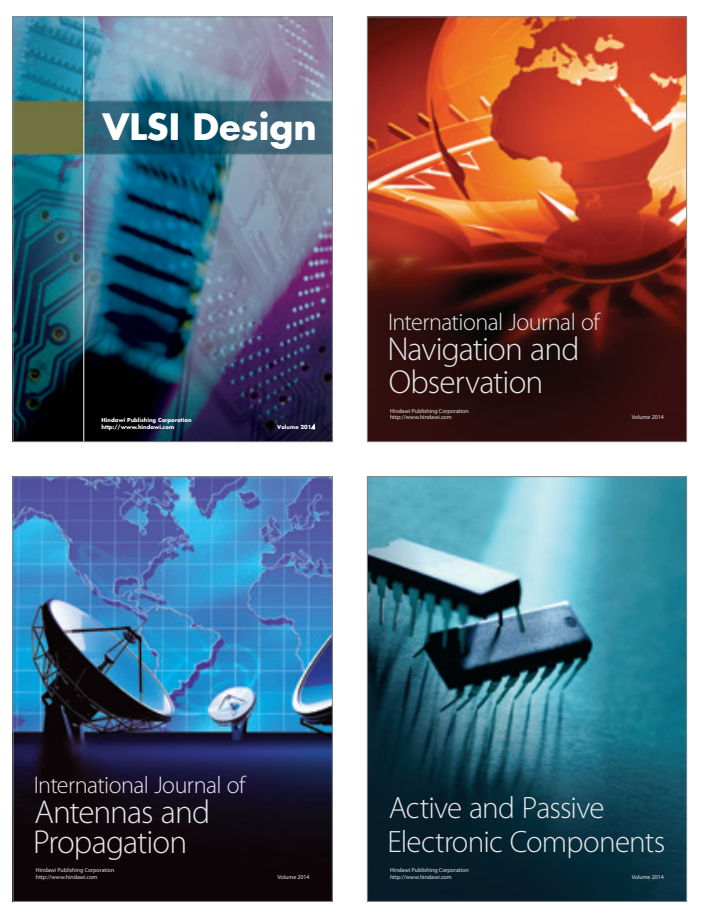
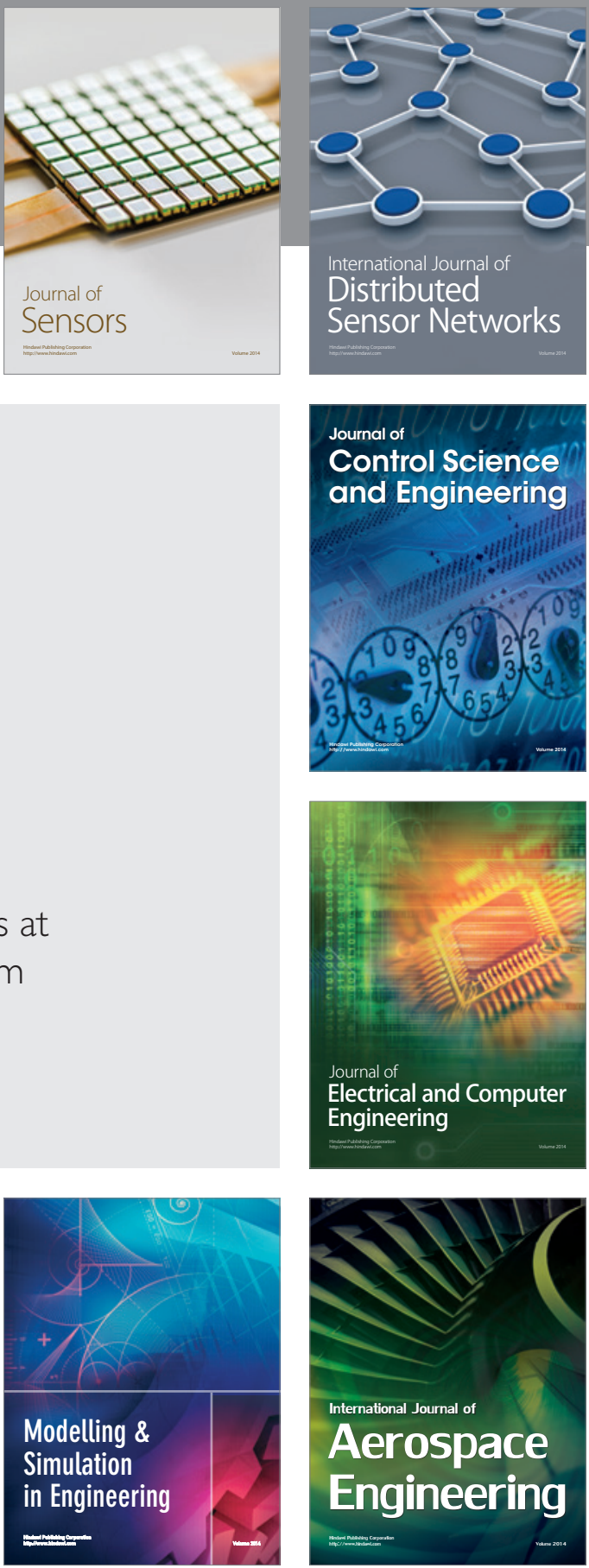

Journal of

Control Science

and Engineering
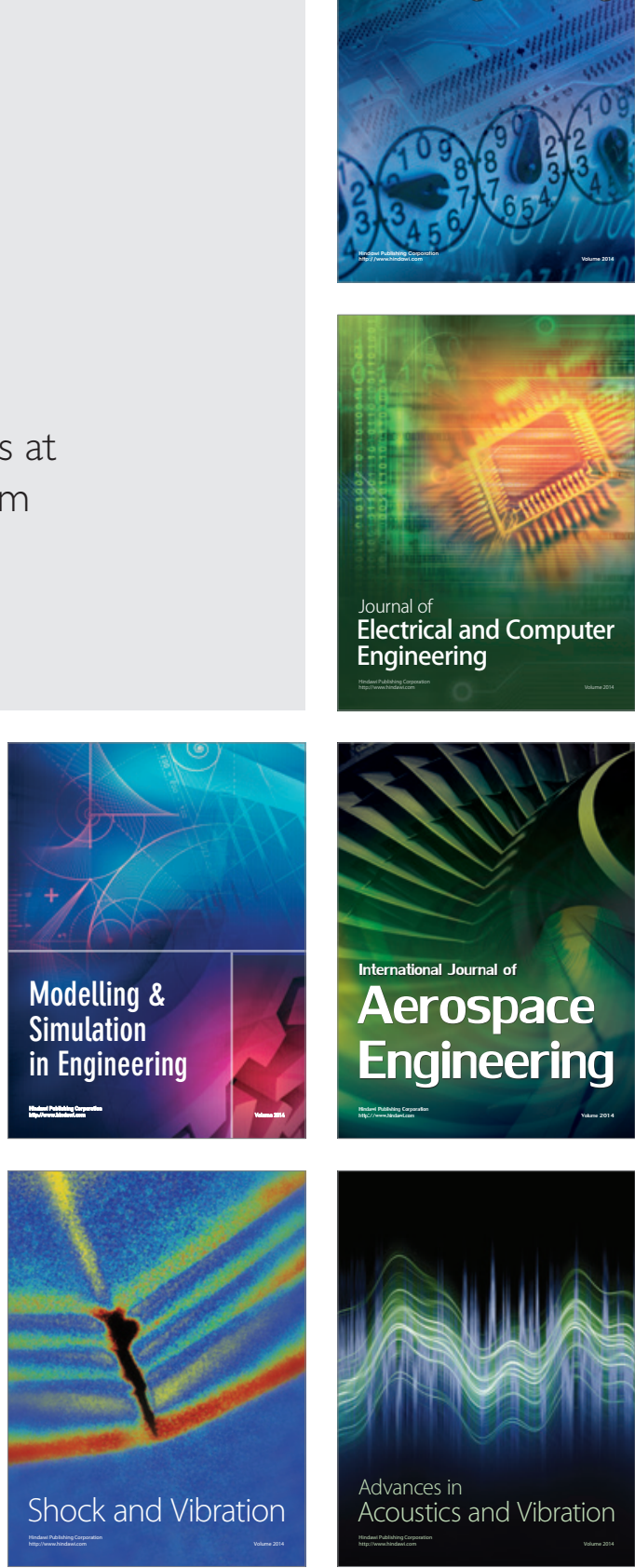